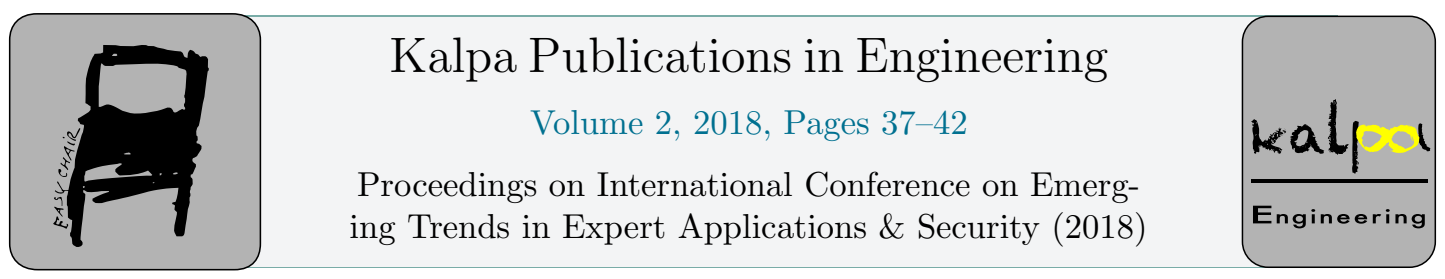

\title{
Utility of Li-Fi in Railways
}

\author{
Arpit Porwal ${ }^{1}$, Garima Ojha ${ }^{2}$, Geet Kalani ${ }^{3}$ \\ ${ }^{1}$ B.Tech Student , ${ }^{2}$ Assistant Professor ${ }^{3}$ \\ Computer Sciemce \& Engineering, JECRC,Jaipur, India 1arpitporwal.2cse19@jecrc.ac.in, \\ 3 geetkalani.cse@jecrc.ac.in, \\ ${ }^{2}$ garimaojha.cse@jecrc.ac.in
}

\begin{abstract}
The Li-Fi is another remote innovation to give the availability with in restricted system condition. The primary rule of this innovation is we can transmit the information utilizing light brightening by utilizing light-producing diodes where radio recurrence is media in Wi-Fi and Driven globule light power is speedier than human eye can take after. Prof Harald Haas a specialist in optical remote correspondences at the University of Edinburgh, he was shown how a LED globule furnished with flag handling innovation could stream a top quality video to a PC. By utilizing this innovation a onewatt Driven light would be sufficient to give net network to four PCs. He begat the term "light constancy" or li-fi and set up a privately owned business, Unadulterated VLC, to misuse the innovation. . He imagines a future where information for workstations, PDAs, and tablets is transmitted through the light in a room. What's more, security would be snap - on the off chance that you can't see the light, you can't get to the information.
\end{abstract}

Keywords: LED, Wi-Fi, VLC.

V.K. Chandna, V.S. Rathore and S. Maheshwari (eds.), ICETEAS 2018 (Kalpa Publications in Engineering, vol. 2), pp. 37-42 


\section{Introduction}

Presently a day's Wi-Fi is generally utilized as a part of all people in general zones like home, bistros, inns, air terminals. Because of this radio recurrence is getting blocked step by step, at the same time use of remote information is expanding exponentially consistently. Everybody is intrigued to utilize remote information however the limit is going down. Remote radio frequencies are getting higher, complexities are expanding and RF impedances keep on growing. Keeping in mind the end goal to beat this issue in future, light - loyalty (Li-Fi) innovation came into presence since 2011 [1] [8]. Li-Fi is a remote correspondence framework in which light is utilized as a bearer motion rather than conventional radio recurrence as in $\mathrm{Wi}-\mathrm{Fi}$. Li-Fi is an innovation that utilizations light producing diodes to transmit information remotely. Unmistakable light correspondence (VLC) utilizes fast beats of light to transmit data remotely that can't be identified by human eye. This paper will concentrate on Li-Fi innovation over Wi-Fi innovation VLC innovation. Li-Fi stands for 'Light Fidelity'. it's a VLC (Visible lightweight Communication), technology developed by team of scientists as well as Dr. Gorden Povey, Prof. Harald Hass and Dr. Mostafa Afgani at University of capital. Li Fi is currently a part of visible radiation Communication (VLC) PAN IEEE802.15.7 Standard. Li-Fi is usually enforced mistreatment white crystal rectifier lightweight bulbs. These device square measure ordinarily used for illumination by Appling a continuing current through the crystal rectifier. Li-Fi, this term are wont to label the quick and low cost wireless communication system, that is that the optical version of Wisconsin -Fi, Li-Fi is lightweight based mostly Wi-Fi that's, it uses lightweight rather than radio waves to transmit data.

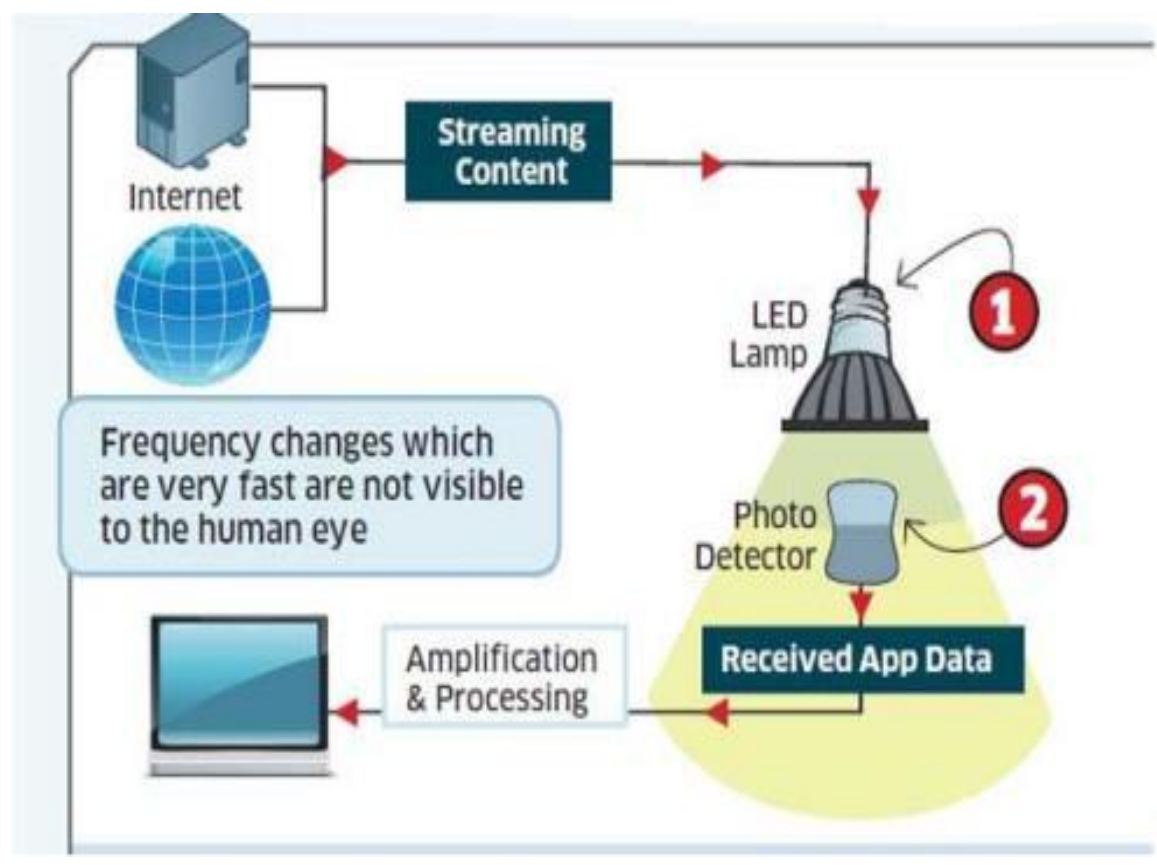

Fig : Li-Fi Technology 


\section{Literature Survey}

A large portion of us know about Wi-Fi (Wireless Constancy), which utilizes 2.4-5GHz RF to convey remote Web access around our homes, schools, workplaces and openly puts. We have turned out to be very reliant upon this almost universal administration. In any case, as most Innovations, it has its confinements [1][2][3].

While Wi-Fi can cover a whole house, its data transmission is commonly constrained to 50-100 megabits for each second (Mbps) today utilizing the IEEE802.11n standard. This is a decent match to the speed of most current Internet administrations, yet deficient for moving vast information records like HDTV motion pictures, music libraries what's more, computer games [4][8].

The more we end up plainly subordinate upon 'the cloud' or then again our own 'media servers' to store the majority of our documents, counting motion pictures, music, pictures and recreations, the more we will need transmission capacity and speed. Along these lines RF-based advancements, for example, the present Wi-Fi are definitely not the ideal way. Moreover, Wi-Fi may not be the most proficient approach to give new wanted capacities for example, accuracy indoor situating and motion acknowledgment. [5][6][9]

\section{Working of Li-Fi [1-8]}

Data from the net and therefore the native network is employed to modulate the intensity of semiconductor diode light in an exceedingly method undetectable to the human eye. The photodetector picks up the signal that is regenerate back to an information stream and sent to the consumer. The consumer will communicate through its own semiconductor diode output or over the prevailing network. Operational procedure is extremely easy, if the semiconductor diode is on, you transmit a digital one, if it's off you transmit a zero. The LEDs will be switched on and off terribly quickly, which provides nice opportunities for transmittal information. thus all that's needed is a few LEDS and a controller that code information into those LEDs. We've to simply vary the speed at that the LED's flicker relying upon the info we would like to write in code. Therefore each light can works as a hub for information transmission.

On one finish all \{the information the info the information\} on the net are going to be streamed to a lamp driver once the semiconductor diode is turned on the semiconductor converts the digital information in style of light-weight sensitive device (photo detector) receives the signal and converts it back to original data. This methodology of mistreatment fast pulses of sunshine to transmit info wirelessly is technically referred as visible radiation Communication 


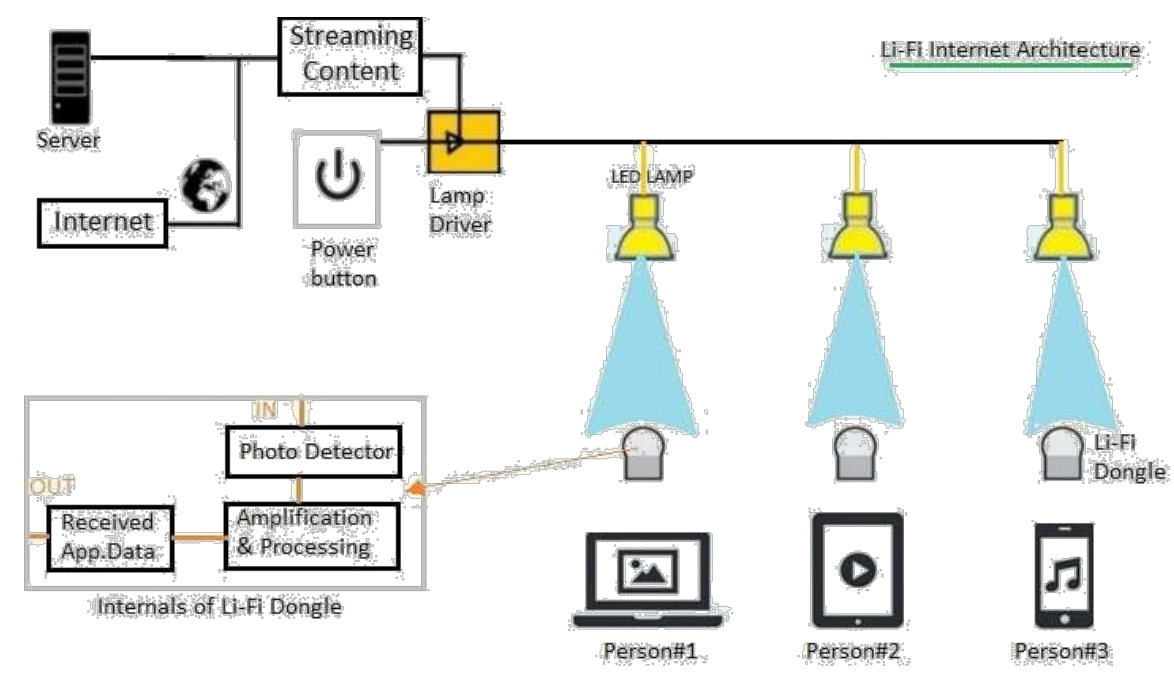

\section{Comparison between $\mathrm{Li}-\mathrm{Fi}$ and $\mathrm{Wi}-\mathrm{Fi}$}

\begin{tabular}{|l|l|l|}
\hline Parameter & LI-FI & WI-FI \\
\hline Speed & $* * *$ & $* * *$ \\
\hline Range & $* * *$ & $* *$ \\
\hline Data Density & $* * *$ & $*$ \\
\hline Security & $* * *$ & $* *$ \\
\hline Reliability & $* *$ & $* *$ \\
\hline $\begin{array}{l}\text { Power } \\
\text { available }\end{array}$ & $* * *$ & $* *$ \\
\hline $\begin{array}{l}\text { Transmit/Rec } \\
\text { iv } \\
\text { e power }\end{array}$ & $* * *$ & $* *$ \\
\hline $\begin{array}{l}\text { Ecological } \\
\text { Impact }\end{array}$ & $*$ & $* *$ \\
\hline $\begin{array}{l}\text { Device to } \\
\text { device } \\
\text { connectivity }\end{array}$ & $* * *$ & $* * *$ \\
\hline $\begin{array}{l}\text { Obstacle } \\
\text { interference }\end{array}$ & $* * *$ & $*$ \\
\hline $\begin{array}{l}\text { Bill of } \\
\text { materials }\end{array}$ & $* * *$ & $* *$ \\
\hline
\end{tabular}




\section{Application of Li-Fi in Indian Railways}

Railways Minister Suresh Prabhu has declared that Wi-Fi facilities would be provided at over four hundred railway stations. Presenting the Railway allow commercial enterprise 2015-16 in Parliament, Prabhu said: "This budget is for speedier railway, 9 high-speed corridors, high speed trains, and create in Asian country opportunities. there'll be satellite railway terminals in major cities - ten choose stations and Wi-Fi facility are provided in four hundred stations."

According to Indian Railway budget 2015; all station are having LAN hotspot. thus so as to support this budget set up we'd wish to introduce our construct Li-Fi. until date two hundred stations ar having Wi-fi facilities and two hundred stations ar left to be equipped with Wi-Fi. All station take issue i.e. long of station, range of platform on a station thus their perhaps use of the many routers or net access points, however by victimization $\mathrm{Li}$-Fi construct we will cut back the router amount and additionally we will have common access purpose for every station. The profit are information transmission are through light-weight, thus there are often light-emitting diode lights on all station.

\section{Future Scope}

The dramatic growth within the use of LEDs (Light Emitting Diodes) for lighting provides the chance to include Li-Fi technology into a excessiveness of LED environments.

Li-Fi is especially appropriate for several common web "content consumption" applications like video and audio downloads, live streaming, etc. These applications place serious demands on the downlink information measure, however need token transmission capability. during this manner, the bulk of the net traffic is off-loaded from existing RF channels, therefore conjointly extending cellular and Wi-Fi capacities.

There square measure several applications and future scope for Li-Fi. These include:

Smart Lighting: Any personal or public lighting together with street lamps is accustomed offer Li-Fi hotspots and also the same communications and sensing element infrastructure is accustomed monitor and management lighting and information.

Mobile Connectivity: Laptops, sensible phones, tablets and alternative mobile devices will interconnect directly exploitation VLC. Short vary links offer terribly high information rates and conjointly provides security.

Hazardous Environments: VLC provides a secure different to magnetic force interference from frequency communications in environments like mines and organic compound plants. 
Hospital \& Healthcare: VLC emits no magnetic force interference and then doesn't interfere with medical instruments, nor is it interfered with by tomography scanners.

Aviation: Li-Fi is accustomed cut back weight and cabling and add flexibility to seating layouts in craft traveler cabins wherever LED lights square measure already deployed. In-flight amusement (IFE) systems can even be supported and integrated with passengers' own mobile devices.

Underwater Communications: as a result of sturdy signal absorption in water, RF use is impractical. Acoustic waves have very low information measure and disturb marine life. Li-Fi provides an answer for short-range communications.

Vehicles \& Transportation: LED headlights and tail-lights square measure being introduced. Street lamps, accumulation and traffic signals also are moving to LED. this will be used for vehicle-tovehicle and vehicle-to-roadside communications. this will be applied for road safety and traffic management.

\section{Conclusion}

On implementing this technology it's potential to use each bulb as a hotspot that produces safer surroundings. As radio waves square measure venturesome to living creatures and results in endangering of birds we have a tendency to attempt to scale back this complication victimization light-weight fidelity that works on actinic ray frequency and doesn't damage the character. Another advantage of sunshine fidelity is reduction within the power consumption and transfer of knowledge at higher rate that Wi-Fi finds tough to achieve. victimization this technology in medical field makes diagnosing quicker and permits to access net in conjunction with the radio waves based mostly devices. There square measure disadvantages too during this technology i.e. there ought to be a specific line of sight and additionally reckoning on the bulb used potency differs. Therefore, with the implementation of this technology its potential to unravel problems like the shortage of radiofrequency information measure and additionally permit net wherever ancient radio based mostly wireless isn't allowed like craft or hospitals.

\section{References}

1.Schnichiro Haruyama, 'Visible light communication, Recent activities in Japan',Smart spaces: A smart lighting ERC industry-Academia day at BU Photonics center, BostonUniversity, Feb 8, 2011.

2.Harald Haas, 'Wireless data from every light bulb', TED Global, Edinburgh, July 2011.

3.http://electronicsforu.com/electronicsforu

4.http://en.wikipedia.org/wiki/Li-Fi

5."New Epoch of wireless communication: Light Fidelity”IJIRCCE, vol 1,issue 2,April 2013.

6."LI-FI" the latest technology in wireless"IJCCE, vol 2 issue 3, july,2012.

7. www.lificonsortium.org.

8. seminarprojects.com/s/seminar-report-on-lifi.

9. Dvice.com/archives/2012/08/lifi-ten-ways-i.php 